\title{
APLIKASI PENDETEKSI PLAGIARISME TUGAS DAN MAKALAH PADA SEKOLAH MENGGUNAKAN ALGORITMA RABIN KARP
}

\section{Plagiarisme Detection Applications For Tasks and Problems in School Using Rabin Karp Algorithm}

\author{
Danny Steveson1), Halim Agung, hagung@ bundamulia.ac.id 2), Fendra Mulia3) \\ ${ }_{112) 33}$ Teknik Informatika / Fakultas Teknologi dan Desain, Universitas Bunda Mulia
}

\begin{abstract}
Plagiarism is a very frequent problem in all aspects of one occurring in school. There is often plagiarism on the content of the papers or assignments collected by the students. This is to support the decreasing creativity of students in giving ideas and personal opinions on the task given. To answer the above problems then this research using Rabin-Karp algorithm. Rabin-Karp algorithm is a string search algorithm that uses hashing to find one of a series of string patterns in text. Using this application, the user can compare document 1 with another document, which gives results in sentence similarity, then spelled out per word, followed by per hashing and is calculated from the average number of percentages. The test in this research is done by taking samples 50 times and in comparison between percentage with Rabin Karp algorithm and percentage with manual taking. Testing is done by comparing one document with another document. Based on the result of the research, it can be concluded by using Rabin Karp Algorithm, which can be implemented in plagiarism application evidenced by the test using 50 test samples with 43 samples of success of $14.22 \%$.
\end{abstract}

Keywords: document, Rabin Karp Algorithm, Dice Sorensen Index, Plagiarism, sentence, word

\begin{abstract}
ABSTRAK
Plagiarisme merupakan permasalahan yang sangat sering terjadi di semua aspek salah satunya terjadi di sekolah. Seringkali terjadi plagiat terhadap konten karya tulis atau tugas yang dikumpulkan oleh siswa. Hal ini menjadi penunjang berkurangnya kreatifitas siswa dalam memberikan ide dan pendapat pribadi pada tugas yang diberikan. Untuk menjawab permasalahan diatas maka penelitian ini menggunakan algoritma Rabin-Karp. Algoritma Rabin-Karp adalah algoritma pencarian string yang menggunakan hashing untuk menemukan salah satu dari serangkaian pola string dalam teks. Dengan menggunakan aplikasi ini, pengguna bisa membandingkan dokumen 1 dengan dokumen yang lain, yang memberikan hasil berupa kesamaan kalimat, kemudian diuraikan dengan per kata, dilanjutkan dengan per hashing dan dihitung dari jumlah rata-rata persentase. Pengujian pada penelitian ini dilakukan dengan pengambilan sampel sebanyak 50 kali dan di bandingkan antara persentase dengan algoritma Rabin Karp dan persentase dengan pengambilan manual. Pengujian dilakukan dengan membandingkan dokumen satu dengan dokumen yang lain. Berdasarkan hasil penelitian, dapat ditarik kesimpulan dengan menggunakan Algoritma Rabin Karp, yang mana dapat diimplementasikan pada aplikasi plagiarisme dibuktikan dengan penggujian menggunakan sampel uji sebanyak 50 kali dengan 43 sampel keberhasilan sebesar 14,22\%.

Kata Kunci: dokumen, Algoritma Rabin Karp, Dice Sorensen Index, Plagiarisme, kalimat, kata
\end{abstract}

\section{PENDAHULUAN}

Plagiarisme ada beberapa cara yang dilakukan untuk mengatasi permasalahan ini, yaitu dengan mencegah dan mendeteksi. Mencegah berarti menjaga atau menghalangi agar plagiarisme tidak dilakukan. Mendeteksi berarti melakukan usaha untuk menentukan tindakan plagiat yang telah dilakukan.

Namun di sisi lain, seringkali terjadi plagiat terhadap konten karya tulis atau bahkan tugas yang di kumpul. Hal ini berujung pada kurang nya kreatifitas siswa dalam menuangkan ide dan pendapat pribadi ke dalam konten yang ingin 
disampaikan. Juga permasalahan seringkali terjadi dengan duplikasi hak cipta. Hal ini berdampak pada sisi siswa, dimana nanti ke depan dalam menuangkan pendapatnya akan sulit terutama ketika dimintai pendapat pribadi. Penelitian ini tentunya tidak sendiri. Dengan melihat penelitian pada sebelumnya didapatkan beberapa data dan teori yang mendukung jalannya riset ini. Berikut disampaikan penelitian terdahulu seperti Pembuatan Sistem Penilaian Otomatis Pada Jawaban Ujian Berbentuk Esai Menggunakan Metode Rabin Karp [1] yang mendeteksi ujian dari siswa antara jawaban siswa satu dengan siswa yang lain dengan hasil akhir berupa kemunculan merah dan persentase yang berlaku, Pendeteksian Plagiarisme Teks [2] dengan menggunakan algoritma SmithWaterman untuk mendeteksi kesamaan dokumen dan data noise untuk menghitung bobot hasil perbandingan, Pembuatan Sistem Deteksi Plagiarisme Dokumen Teks dengan Menggunakan Algoritma Rabin Karp [3] yang menghasilkan $K$-Gram untuk mendeteksi kesamaan dokumen dan cara perhitungan lebih menggunakan K-Gram serta persentase error (toleransi kesalahan), Aplikasi anti plagiarisme dengan algoritma Karp-Rabin pada penulisan ilmiah Universitas Gunadarma [4] menunjukkan bahwa algoritma Rabin-Karp bertujuan untuk mencari presentase kesamaan dua file yang ada.

\section{METODE PENELITIAN}

\section{Plagiarisme}

Menurut Sastroasmoro [5], plagiarisme adalah penggunaan ide, pikiran, data, kalimat orang lain seolah-olah sebagai miliknya tanpa menyebutkan sumbernya. Plagiarisme merupakan salah satu pelanggaran serius yang bersifat universal terhadap etika akademis (scientific misconduct). Tindakan plagiarisme ini merupakan sebuah tindakan tercela, karena merupakan ketidakjujuran alias kebohongan. Perkembangan pesat pada dunia teknologi dan informasi memudahkan kita untuk memperoleh berbagai macam informasi. Internet sangat berguna sebagai sumber informasi dalam mencari berita, serta mencari referensi untuk membantu pembuatan tugas dan karya tulis. Namun, hal tersebut terkadang dimanfaatkan oleh sebagian orang untuk kepentingannya sendiri, seperti tindakan plagiarisme dalam pengerjaan tugas dan karya tulis. Secara garis besar, plagiarisme dapat dikelompokkan menjadi 2, yaitu plagiarisme ide dan plagiarisme kata demi kata (word for word plagiarizing). Derajat plagiarisme yang paling berat adalah word for word plagiarizing yakni pencurian kata demi kata, yang dapat mencakup kalimat, paragraf, atau seluruh tulisan [5]. Sedangkan, dalam karya tulis ilmiah, plagiarisme ide sering dihubungkan dengan laporan hasil penelitian replikatif, yaitu penelitian yang secara garis besar mengulang penelitian orang lain, dengan maksud untuk menambah data, menguji hasil hipotesis [5]. Ada beberapa definisi tentang pengertian plagiarisme menurut para ahli, diantaranya:

1. Plagiarisme adalah berbuat sesuatu seolah-olah karya orang lain tersebut adalah karya sendiri dan mengakui hasil karya tersebut [6].

2. Pengertian plagiarisme adalah bentuk penyalahgunaan hak kekayaan intelektual milik orang lain, yang mana karya tersebut direpresentasikan dan diakui secara tidak sah sebagai hasil karya pribadi [7].

\section{Preprocessing}

Pengertian Preprocessing [8] adalah proses perubahan bentuk data yang terstruktur sembarang menjadi data yang terstruktur sesuai kebutuhan untuk proses dalam text mining. Tahap preprocessing terdiri dari case folding, tokenizing, filtering, dan stemming. Penelitian ini menggunakan tahap case folding hingga stemming. Case Folding adalah tahap mengubah semua huuf dalam dokumen menjadi huruf kecil. Selain itu, karakter non-huruf akan dihilangkan. Tokenizing adalah tahap pemecahan kalimat berdasarkan tipe kata yang menyusunnya. Filtering adalah tahap mengambil kata-kata penting dari hasil tahap tokenizing . Filtering dapat dilakukan dengan 
menghilangkan stoplist/stopword (kata-kata yang tidak deskriptif, seperti kata "yang" dan "dari"). Stemming adalah tahap transformasi suatu kata menjadi kata dasarnya (root word) dengan menggunakan aturan-aturan tertentu.

\section{Algoritma Rabin Karp}

Algoritma Karp-Rabin [9] adalah algoritma pencarian string yang menggunakan hashing untuk menemukan salah satu dari serangkaian pola string dalam teks. Untuk teks panjang $\mathrm{n}$ dan $\mathrm{p}$ pola gabungan panjang $\mathrm{m}$, rata-rata dan kasus terbaik waktu berjalan adalah $(\mathrm{n}+\mathrm{m})$ di ruang $\mathrm{O}(\mathrm{p})$, tapi kali terburuk adalah $\mathrm{O}$ $(\mathrm{nm})$. Sebaliknya algoritma pencocokan string Aho-Corasick memiliki asymptotic terburuk waktu kompleksitas $\mathrm{O}(\mathrm{n}+\mathrm{m}) \mathrm{di}$ ruang $\mathrm{O}(\mathrm{m})$. sebuah aplikasi praktis dan algoritma ini mendeteksi plagiarisme. Mengingat bahan sumber, algoritma cepat dapat mencari melalui kertas untuk contoh kalimat dari bahan sumber, mengabaikan rincian seperti kasus dan tanda baca. Karena kelimpahan string dicari, algoritma pencarian tunggal string tidak praktis. Algoritma Rabin-Karp adalah salah satu algoritma yang dapat digunakan untuk mencari dimana sebuah string (dalam kasus ini dinamakan sebagai pola) apakah ditemukan di dalam kumpulan string lain dengan ukuran yang lebih besar. Contoh yang dibahas kali ini adalah mengenai pencarian kata dari sebuah input teks. Untuk mempercepat pencarian pola dalam kalimat, Rabin-Karp menggunakan Metode hash. Metode ini mengubah setiap string menjadi angka, yang dinamakan nilai hash. Apabila 2 string adalah sama persis, maka nilai hashnya juga akan sama, sehingga pencarian string dapat diturunkan dengan cara menghitung nilai hash dari pola, dan kemudian melakukan pencarian pola dengan nilai hash yang sama pada data input. Langkah-langkah algoritma rabin karp adalah sebagai berikut :

1. Menghilangkan tanda baca dan mengubah ke teks sumber dan kata yang ingin dicari menjadi kata-kata tanpa huruf kapital yang dapat dilihat pada gambar 1.

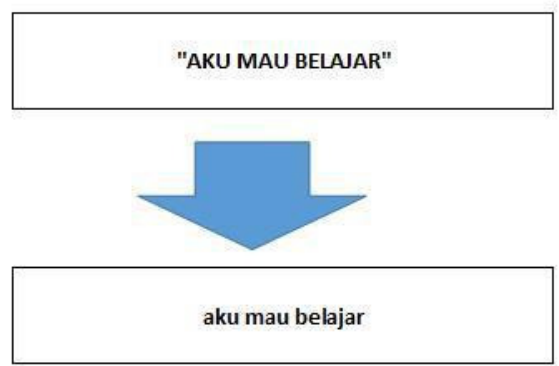

Gambar 1 Proses Algoritma Rabin Karp Pertama

2. Membagi teks ke dalam gram-gram yang ditentukan nilai $k$-gram nya yang dapat dilihat pada gambar 2 .

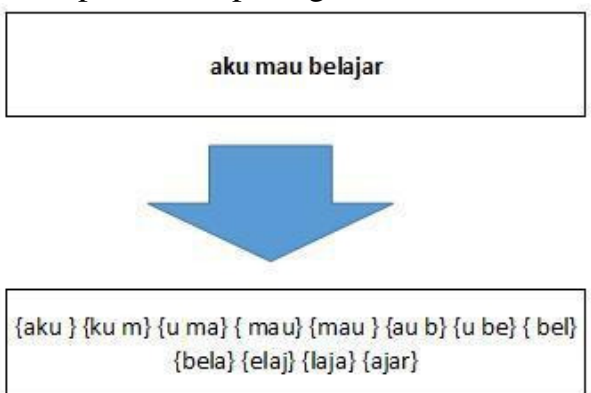

Gambar 2 Proses Algoritma Rabin Karp kedua

3. Mencari nilai hash dengan fungsi rolling hash dari tiap gram yang terbentuk yang dapat dilihat pada gambar 3.

\{aku $\}\{k u m\}\{u$ ma $\}\{$ mau $\}\{$ mau $\}\{$ au b $\}\{u$ be $\}\{$ bel $\{$ bela $\}$ elaj\} \{laja\} \{ajar\}

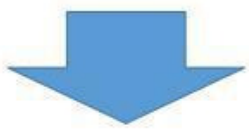

14337315703516089556965158135143714 16077855669143944148672156748143114

Gambar 3 Proses Algoritma Rabin Karp ketiga

4. Mencari nilai hash yang sama diantara kedua teks.

5. Menentukan persamaan 2 buah teks dengan persamaan Sorensen Dice Coefficient. Mengukur kemiripan dan 
jarak antara dua entitas. Dalam perhitungan nilai similarity yang dapat dilihat pada rumus (1).

$$
\mathrm{S}=\frac{\mathrm{K} * \mathrm{C}}{(\mathrm{A}+\mathrm{B})} \times 100 \%
$$

\section{Metode Sorensen Dice Coefficient}

Metode sorensen dice coefficient [10] atau nama lainnya Dice Similarity Coeffcient. Untuk menghitung kemiripan dapat digunakan Dice Similarity Coeficients dengan cara menghitung jumlah K-Gram yang digunakan pada kedua dokumen yang diuji. Nilai kemiripan tersebut dapat dihitung dengan rumus: dimana $\mathrm{S}$ adalah nilai kemiripan, C adalah jumlah $K$-Gram yang sama dan A serta B masing-masing adalah jumlah $K$-Gram dari masing-masing string yang diujikan. Hasil yang didapat adalah bilangan dari 0 sampai 100 dimana bilangan tersebut adalah persentase kemiripan 2 string yang diujikan.

\section{Flowchart Algoritma}

Perancangan flowchart yang menjelaskan cara kerja programnya dapat dilihat pada gambar 4 .

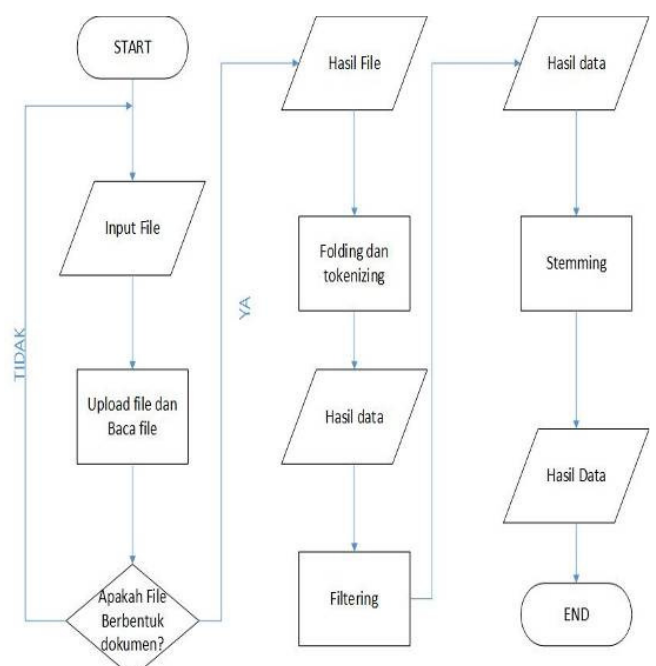

\section{Gambar 4 Flowchart Aplikasi}

Kemudian pada proses flowchart algoritma Rabin Karp dijelaskan secara detail nya pada gambar 5 .

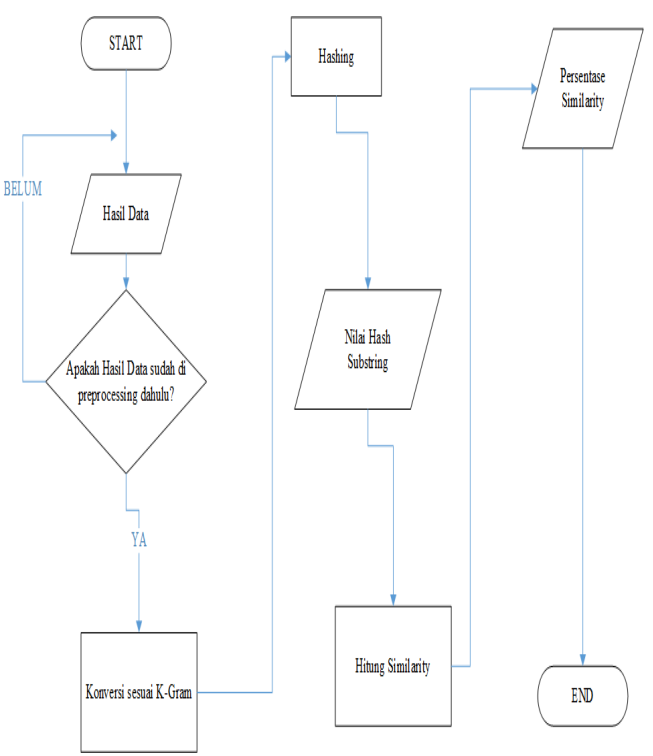

Gambar 5 Flowchart Algoritma

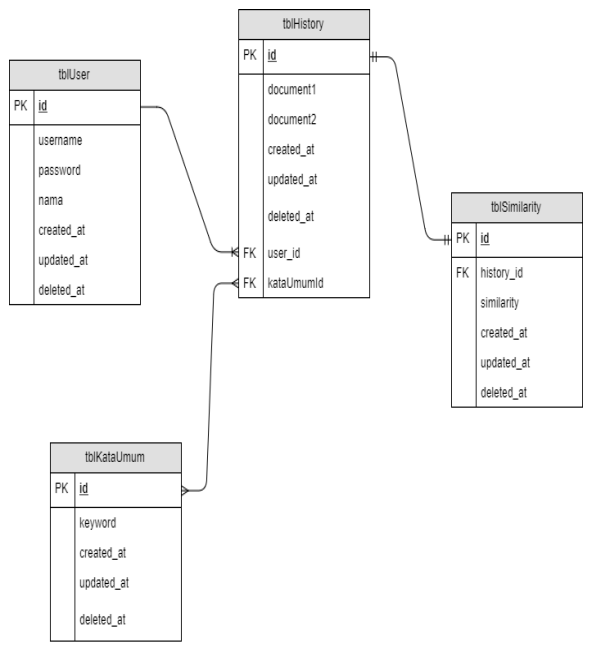

Gambar 6 Entity Relationship Diagram

\section{Entity Relationship Diagram (ERD)}

Gambar 6 menjelaskan tentang keterkaitan tabel yang di buat dalam aplikasi ini. Tabel yang dipakai terdiri dari tabel user, tabel history, tabel kata umum, dan tabel similarity. Untuk tabel user ke tabel history menggunakan rule one to many. Sedangkan untuk tabel kata umum dengan tabel history menggunakan rule many to many, dan yang terakhir tabel 


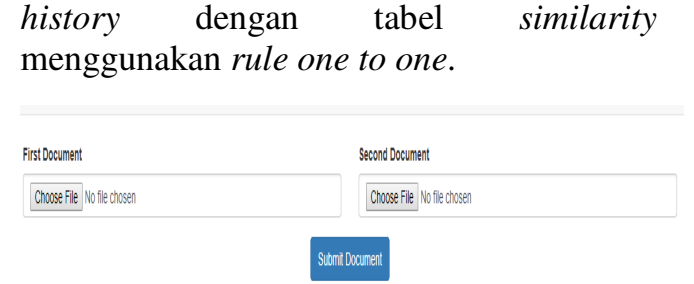

Gambar 7 Tampilan Awal Aplikasi

\section{HASIL DAN PEMBAHASAN}

Pada penelitian yang dilakukan pada aplikasi plagiarisme, mendapatkan hasil desain dan tampilan sesuai dengan kebutuhan. Terlihat pada gambar 7 merupakan tampilan awal pada aplikasi pendeteksian plagiarisme.

Gambar 7 merupakan tampilan tempat user memasukkan dokumen yang akan dibandingkan baik dokumen sumber maupun dokumen yang dibandingkan. Setelah dokumen - dokumen tersebut dimasukkan maka dokumen tersebut akan langsung memasuki tahap pemilihan dengan melakukan sortir kalimat mana saja yang sama yang terdapat pada dokumen sumber dan diberi warna merah. Seperti yang terdapat pada gambar 8 .

Kemudian dokumen tersebut melalui tahap hashing sesuai dengan proses algoritma rabin-karp yang hasilnya berupa angka hash. hasil hash dari 2 data yang sudah di proses, dan dapat ditemukan persamaan dari 2 data. hasil persentase hasil hash 2 data yang sudah di submit, dan persamaan yang ada menjadi persentase dari Sorensen Index Similiarity yang dapat dilihat pada gambar 9.

Adapun berikut tabel dari hasil 3 dari 50 pengujian yang menunjukkan hasil pengujian antara manual dengan pengujian berdasarkan sistem dengan algoritma Rabin Karp dapat dilihat pada tabel 1.

Berdasarkan hasil pengujian tersebut, dapat ditemukan rata-rata persentase plagiarisme dengan menggunakan algoritma Rabin Karp mendapatkan hasil sebesar 14,21\% dan persentase pendeteksian plagiarisme secara manual diperoleh sebesar 13,22\%. Adanya perbedaan persentase yang terjadi menghasilkan angka sebesar $0,99 \%$.
Document 1:

Jakarta - Daihatsu Sigra semakin hangat dibicarakan setelah satu kasus yang dialaminya. Bayangkan saja, beberapa Daihatsu Sigra mengalami kejadian kaca belakangnya tiba-tiba pecah. Daihatsu pun pastikan jika ada yang mengalami hal tersebut maka Daihatsu siap bertangoung jawab. Meski demikian, PT Astra Daihatsu Motor (ADM) pastikan, kejadian serupa tidak akan terjadi pada model Dainatsu lainnya dan menjadi kejadian pertama yang dialami Daihatsu. Seperti yang disampaikan Direktur Marketing ADM, Amelia Tjandra. "Tidak. Mobil Dainatsu yang lain diyakinkan tidak mengalami hal serupa seperti Dahihatsu Sigra ini," katanya dikawasan Jakarta Utara. Amel menjelaskan, kejadian ini itidak akan terjadi pada model Daihatsu lainnya. Hal ini dikarenakan bentuk desain kaca belakang masing-masing model Dainatsu berbeda "Karena bentuk kacanya berbeda (dari mobil Daihatsu lainnya), jadi handle-nya berbeda (proses produksi-nya). Baru kall pertama juga Daihatsu mengalami hal seperti ini," lanjut Amel. Sebelumnya, pihak ADM mendapatkan laporan terkait kasus pecahnya kaca belakang Daihatsu Sigra dengan sendirinya pada November 2016. Setelah dilakukan pengecekan dan penanganan, muncul lagi hal serupa pada 280 Kktober 2017. Setelah diselidiki, permasalahan memang muncul dari kesalahan pihaknya saat melakukan handling pada bagian kaca belakang Sigra. Sejalan dengan hal tersebut, pihak ADM telah merampungkan beberapa solusi untuk menanganinya. Olen karena ittu, diharapkan peristiwa serupa tak terjadi lagi. Nah, bagi Otolovers yang memiliki mobil serupa dan mengalami peristiwa seperti itu, pihak ADM menyarankan agar langsung dibawa ke diler resmi terdekat. Agar dilakukan penanganan dan seluruh biaya ditanggung oleh Daihatsu.
Document 2:

Model mobil Daihatsu rusak oleh Fahri Hamzah. Bayangkan saja, beberapa Daihatsu Sigra mengalami kejadian kaca belakangnya tiba-tiba pecah. Meski demikian, PT Astra Daihatsu Motor (ADM) pastikan, kejadian serupa tidak akan teriadi pada model Daihatsu lainnya, dan menjadi kejadian pertama yang dialami Daihatsu. Amel menjelaskan, kejadian ini tidak akan terjadi pada model Daihatsu lainnya. Hal ini dikarenakan bentuk desain kaca belakang masing-masing model Daihatsu berbeda. Bentuk kaca berbeda tapi tetap pecah meskipun tidak kejadian. Baru kali pertama juga Daihatsu mengalami hal seperti ini," lanjut Amel. Setelah dilakukan pengecekan dan penanganan, muncul lagi hal serupa pada 28 Oktober 2017. Setelah diselidiki, masalah memang muncul dari kesalahan pihaknya saat melakukan handling pada bagian kaca belakang Sigra. Sejalan dengan hal tersebut, pihak ADM telah merampungkan beberapa solusi untuk menanganinya. Semoga kejadian tersebut tidak terulang lagi. Nah, bagi Otolovers yang memiliki mobil serupa dan mengalami peristiwa seperti itu, pihak ADM menyarankan agar langsung dibawa ke diler resmi terdekat. Servis gratis oleh Daihatsu.

\section{Gambar 8 Tampilan Hasil Dokumen dengan Kesamaan per Kalimat}


Hasil Sorensen Index Similarity

$3.8461538461538 \%$

\section{Gambar 9 Hasil Persentase Kesamaan}

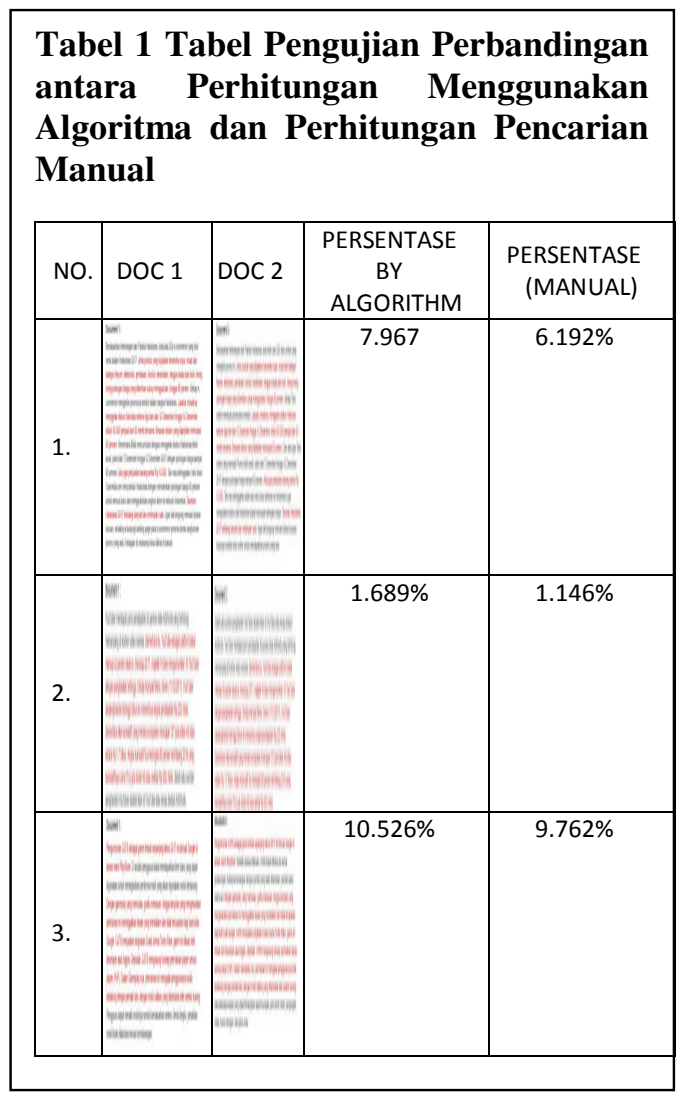

\section{KESIMPULAN}

Berdasarkan hasil penelitian mengenai "Aplikasi Pendeteksi Plagiarisme Tugas dan Makalah Pada Sekolah menggunakan Algoritma Rabin Karp" yang di lakukan melalui observasi, wawancara, dan studi dokumenter. Algoritma Rabin Karp dapat diimplementasikan pada aplikasi plagiarisme dibuktikan dengan penggujian menggunakan sampel uji sebanyak 50 kali dengan 43 sampel keberhasilan sebesar 14,22\%.

\section{DAFTAR PUSTAKA}

[1] Lesmana, DI. (2012), Pembuatan Sistem Penilaian Otomatis Pada Jawaban Ujian Berbentuk Esai Menggunakan Metode Rabin Karp, Jurusan Teknik Informatika, Fakultas Sains dan Teknologi, Universitas Islam Negeri Maulana Malik Ibrahim, Malang.

[2] Novanta, A. (2009), Pendeteksian Plagiarisme Teks, PP. 11-26, Universitas Sumatra Selatan, Medan.

[3] Nugroho, E. (2011), Pembuatan Sistem Deteksi Plagiarisme Dokumen Teks dengan Menggunakan Algoritma Rabin Karp, Program StudiI lmu Komputer, Jurusan Matematika, Fakultas Matematika dan Ilmu Pengetahuan Alam, Universitas Brawijaya Malang, Malang.

[4] Mutiara, dkk. (2014), Aplikasi anti plagiatisme dengan algoritma KarpRabin pada penulisan ilmiah Universitas Gunadarma, Skripsi Program Studi Teknik Informatika.

[5] Sastroasmoro, Sudigdo. (2010). Beberapa Catatan tentang Plagiarisme. Departemen Ilmu Kesehatan Anak, Fakultas Kedokteran Universitas Indonesia. Jakarta.

[6] Novanta, A. (2009), Pendeteksian Plagiarisme Teks, PP. 11-26, Universitas Sumatra Selatan, Medan.

[7] Sulianta, F. (2008). Konten Internet, Elexmedia Komputindo, Jakarta. ISBN : 979271788

[8] Feldman, R \& Sanger, J. (2007). The Text Mining Handbook : Advanced Approaches in Analyzing Unstructured Data. Cambridge University Press : New York.

[9] Benny, R.Joshi. (2010). Simulated Annealing untuk mencari rute jalan 
terpendek dengan biaya minimal. Jurnal ilmu komputer 1(2): 234-137

[10] Nugroho, E. (2011), Pembuatan Sistem Deteksi Plagiarisme Dokumen Teks dengan Menggunakan Algoritma
Rabin Karp, Program Studi Ilmu Komputer, Jurusan Matematika, Fakultas Matematika dan Ilmu Pengetahuan Alam, Universitas Brawijaya Malang, Malang. 